\title{
OBESITY FACTORS (PHYSICAL ACTIVITY AND USUAL DIETARY PATTERN) AND BREAST CANCER IN KOREA
}

\author{
MYEONG SEONG KIM ${ }^{1,2}$, YOUNG HEE NAM² \\ INational Cancer Center, Department of Radiology, Ilsandong-gu, Goyang-si Gyeonggi-do, South Korea \\ ${ }^{2}$ Namseoul University, Department of Public Health Administration, Seonghwan-eup, Seobuk-gu, \\ Cheonan, Chungcheongnam-do, South Korea
}

\begin{abstract}
Mailing address: Young Hee Nam, Namseoul University, Department of Public Health Administration, 91 Daehark-ro, Seonghwan-eup, Cheonan, Chungcheongnam-do, 31020, South Korea, tel.: +82 415802330 , fax: +82 41 5802926, e-mail: yhnaml4@nsu.ac.kr
\end{abstract}

\begin{abstract}
Introduction. This study sought to evaluate the association between obesity factors (food consumption and physical activity) and breast cancer incidence in Korean women. Material and methods. The study included breast cancer patients (250 women) and normal participants undergoing medical checkups ( 250 women) who visited a specialized cancer research hospital between August 1, 2016 and February 15, 2017. Nutrient intake was assessed using a validated food frequency questionnaire (FFQ) covering 112 dishes and foods that Koreans often eat. Physical activity was assessed according to the International Physical Activity Questionnaire (IPAQ) guidelines and was quantified as metabolic equivalent (MET) scores. Results. The results for nutrient intake obtained using the FFQ showed that the control group had a higher consumption of dietary fiber $(\mathrm{p}<0.004)$ and a lower intake of animal fat $(\mathrm{p}<0.02)$ than the breast cancer group. Among breast cancer patients, pre-menopausal women consumed more animal fat $(18.6 \mathrm{~g} \pm 11.9 \mathrm{vs} .14 .7 \mathrm{~g} \pm 8.5, \mathrm{p}<0.03)$ than post-menopausal ones. An analysis of the MET scores with logistic regression revealed that lower physical activity among cancer patients was associated with an increased risk of breast cancer, and this association was greater among post-menopausal $(\mathrm{OR}=2.11, \mathrm{p}<0.001)$ than pre-menopausal women $(\mathrm{OR}=0.85, \mathrm{p}<$ 0.02). Conclusion. Having a high-fat diet and doing less exercise increases the risk of breast cancer, so it is important to prevent the accumulation of fat and maintain proper weight through regular physical activity to lower the incidence of breast cancer.
\end{abstract}

Key words: breast cancer, diet, FFQ, MET, obesity

\section{INTRODUCTION}

Besides thyroid cancer, breast cancer is the leading cancer type in Korea with the highest rate of growth in women. The incidence of breast cancer has increased from 24.5 per 100,000 inhabitants in 1999 to 75.1 per 100,000 inhabitants in 2015 [1]. This contrasts with the incidence of other carcinomas in Korea and developed countries that show a declining trend each year $[1,2]$.

Cancer has been a principal cause of death in Korea since 1983, a change attributed to rapid economic development and lifestyle changes similar to those observed in Western countries [3]. The incidence of breast cancer in Korea remains lower than that in developed countries; however, its incidence is steadily increasing in most Asia-Pacific regions (e.g., Japan, China, and Hong Kong), including in Korea [4].

According to the Korean National Health and Nutrition Survey (KNHANS) for the years 1998-2014, overweight and grade 1 obesity show decreased prevalence whereas grade 2 obesity $\left(B M I \geq 30 \mathrm{~kg} / \mathrm{m}^{2}\right)$ show increased prevalence in women [5].

Numerous factors are associated with the incidence of breast cancer, including increasing age, menarche at early age, menopause at older age, null parity, and family history; however, the commonest modifiable risks factors for breast cancer $(60 \%)$ are factors related to obesity, such as exercise and eating habits $[6,7,8]$. According to several systematic reviews and a World Health Organization (WHO) report, regular leisure activities or exercises (both leisure time and occupational) benefit health and reduce the incidence of breast cancer $[9,10,11,12$, 13]. Furthermore, a recent review article showed that consistent exercise positively affected most cancers, particularly by lowering breast cancer incidence and mortality [14]. Obesity and weight gain are influenced the most by diet and exercise; they are caused by energy imbalance due to daily energy expenditure which is lower than the biological need of the body $[15,16]$

This study aimed to evaluate the prevalence of modifiable breast cancer-related obesity factors, including usual eating habits and exercise, which may affect obesity in Korean women, rather than internal factors.

\section{Material and methods}

\section{Subjects}

This study was a case-control study of patients who visited a specialized cancer research hospital in a metropolitan area between August 1, 2016 and February 15, 2017. Institutional Review Board approval (IRB no. NCC 2014-0124) was obtained from the same institution. Informed consent was confirmed (or waived) by the IRB.

The control group consisted of 116 pre-menopausal women and 134 post-menopausal women without a cancer diagnosis who visited the institution for a medical checkup, while the breast cancer group included 122 pre-menopausal women and 128 post-menopausal women who visited the research center and were diagnosed with breast cancer. There was no statistical difference in age distribution between the cases and controls. 


\section{Survey}

To avoid interpersonal bias, all surveys were conducted by a single researcher who collected data on the subjects' lifestyle behaviors using a food frequency questionnaire (FFQ), as well as gathering personal information related to breast cancer.

Variations in a woman's reproductive history may indicate the risk of developing breast cancer. To determine whether menstruation affected the occurrence of breast cancer, the study participants completed questionnaires on their menopausal status, age at menarche, parity, and breastfeeding. Information was also obtained from electronic medical record (EMR) data, and the body mass index (BMI) was calculated based on the nurse's information sheet that was completed during each admission interview. The FFQ questionnaire was developed for cancer research at the specialized cancer research hospital and was validated in 2012. The questionnaire was based on 112 dishes and foods that Koreans often eat and aimed to quantify the average amount of food and number of meals consumed by one adult per week. Each food and dish was based on the basic recipes in the Computer-Aided Nutritional Analysis Program (CAN-Pro).

The questionnaire items concerned first-degree family, the presence of disease in the last five years, parity, menarche, breastfeeding, education, income, menopause status, occupation, exercise, smoking, alcohol, amount consumed at one time, and meal regularity. The questionnaire used a five-point Likert scale for responses.

The physical activity data from the questionnaire related to physical activity and average metabolic equivalent (MET) scores (a multiple of the resting metabolic equivalent rate) were summarized according to the physical activities recorded (occupation; the performance of regular exercise; exercise type, duration, and frequency per week). The physical activity data were scored from estimates according to the International Physical Activity Questionnaire (IPAQ) [17]. Each activity was assigned a MET score with a standard resting metabolic rate of 1.0 (4.184 $\mathrm{kJ}) \cdot \mathrm{kg}^{-1} \cdot \mathrm{h}^{-1}$ and a range from 0.9 (sleeping) to 19 METs (running at $10.9 \mathrm{mph}$ ). MET was regarded as a resting metabolic rate obtained while sitting, based on the energy cost of actual movement. The MET score was used to classify the MET intensity (light, < 3.3 METs; moderate, 4 METs; vigorous, > 8 METs), frequency (estimated in days per week), and duration (time per day) of physical activities. MET-minute scores are equivalent to kilocalories for a 60-kilogram person. Kilocalories may be obtained from MET-minutes using the following formula: METmin $\times$ (weight in kilograms/60 kilograms).

Table 1 shows an example of the major types of activities converted to MET scores (according to the IPAQ Research Committee) [17].

\section{Analysis}

We analyzed the data collected to evaluate the case and control groups. All means and distributions of demographics and patient characteristics were examined using t- and chi-squared tests. Multiple regression analysis was conducted to determine which variables were associated with breast cancer after using normal transformed variates. Among the relevant variates, odds ratios (ORs) and 95\% confidence intervals (CIs) were analyzed by logistic regression. Statistical analysis was performed using IBM SPSS Statistics for Windows, version 20.0 (IBM Corp., Armonk, NY, USA) and p-values $<0.05$ were deemed to indicate statistical significance.
Table 1. MET energies of physical activities, as modified from those described by Ainsworth [17]

\begin{tabular}{|c|c|c|}
\hline Major activities & Activity type or intensity & MET estimate \\
\hline \multirow{4}{*}{ Occupational } & Vigorous & 8 \\
\cline { 2 - 3 } & Moderate & 4 \\
\cline { 2 - 3 } & Walking (vigorous) & 5 \\
\cline { 2 - 3 } & Walking (moderate) & 3.3 \\
\hline \multirow{4}{*}{ Transport } & Sitting & 1 \\
\cline { 2 - 3 } & Walking & 3.3 \\
\cline { 2 - 3 } & Cycling (vigorous) & 8 \\
\hline \multirow{4}{*}{ Household } & Cycling (moderate) & 6 \\
\hline \multirow{3}{*}{ Leisure } & Vigorous & 3 \\
\cline { 2 - 3 } & Vigorous (weight training) & 4 \\
\cline { 2 - 3 } & Moderate (golf) & 3.3 \\
\hline
\end{tabular}

Table 2. Socio-demographic characteristics of patients with breast cancer and non-cancer controls

\begin{tabular}{|c|c|c|c|c|c|}
\hline & \multicolumn{2}{|c|}{ Breast cancer } & \multicolumn{2}{|c|}{ Control } & \multirow{2}{*}{$p$} \\
\hline & No. & $\%$ & No. & $\%$ & \\
\hline \multicolumn{5}{|l|}{ Age at diagnosis (years) } & 0.35 \\
\hline$<39$ & 28 & 11.2 & 19 & 7.6 & \\
\hline $40-49$ & 101 & 40.4 & 96 & 38.4 & \\
\hline $50-59$ & 79 & 31.6 & 86 & 34.4 & \\
\hline$\geq 60$ & 42 & 16.8 & 49 & 19.6 & \\
\hline \multicolumn{5}{|l|}{ Body mass index $\left(\mathrm{kg} / \mathrm{m}^{2}\right)$} & 0.04 \\
\hline$<20$ & 41 & 16.4 & 43 & 17.2 & \\
\hline $20-24.9$ & 137 & 54.8 & 148 & 59.2 & \\
\hline $25-29.9$ & 57 & 22.8 & 48 & 19.2 & \\
\hline$\geq 30$ & 15 & 6.0 & 11 & 4.4 & \\
\hline \multicolumn{5}{|c|}{ First-degree family history of breast cancer } & 0.03 \\
\hline No & 227 & 90.8 & 236 & 94.4 & \\
\hline Yes & 23 & 9.2 & 14 & 5.6 & \\
\hline \multicolumn{5}{|l|}{ Age at menarche (years) } & 0.01 \\
\hline 12 or less & 26 & 9.8 & 19 & 7.6 & \\
\hline 13 & 45 & 20.0 & 43 & 17.2 & \\
\hline 14 & 54 & 18.3 & 57 & 22.8 & \\
\hline 15 or older & 125 & 52.1 & 131 & 52.4 & \\
\hline \multicolumn{5}{|l|}{ Smoking } & 0.82 \\
\hline Never & 226 & 90.4 & 221 & 88.4 & \\
\hline Past & 16 & 6.4 & 20 & 8.0 & \\
\hline Current & 8 & 3.2 & 9 & 3.6 & \\
\hline \multicolumn{5}{|l|}{ Alcohol } & 0.72 \\
\hline Non-drinker & 148 & 59.2 & 164 & 65.6 & \\
\hline Past drinker & 11 & 4.4 & 15 & 6.0 & \\
\hline Current drinker & 91 & 36.4 & 71 & 28.4 & \\
\hline \multicolumn{6}{|c|}{$\begin{array}{l}\text { Total energy expenditure from recreational physical } \\
\text { activity (MET/week) }\end{array}$} \\
\hline$<0-500$ & 67 & 26.8 & 31 & 12.4 & \\
\hline $500-1000$ & 46 & 18.4 & 84 & 33.6 & \\
\hline $1001-2000$ & 113 & 45.2 & 95 & 38.0 & \\
\hline$>2001$ & 24 & 9.6 & 35 & 14.0 & \\
\hline \multicolumn{6}{|c|}{ Estrogen receptor positivity } \\
\hline Pre-menopausal & 93 & 76.2 & & & \\
\hline Post-menopausal & 66 & 51.5 & & & \\
\hline
\end{tabular}




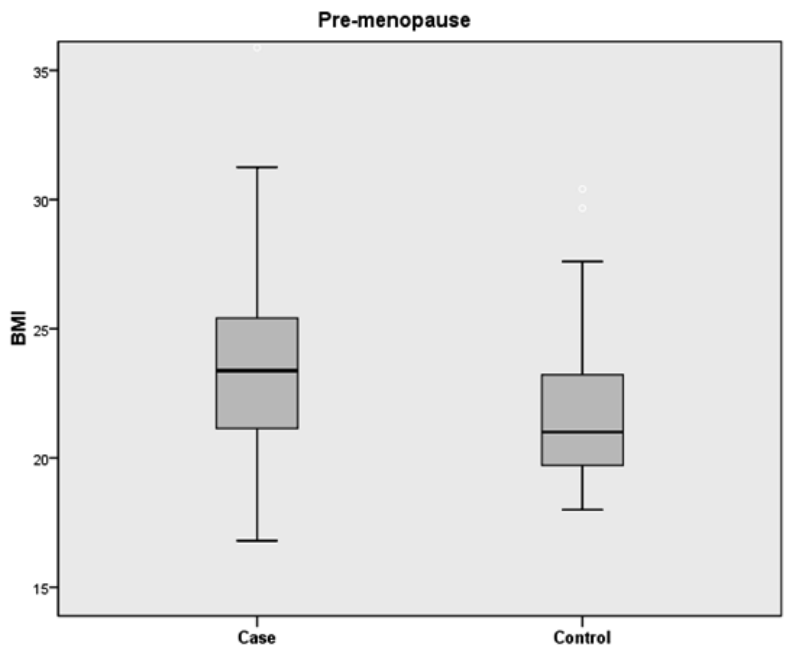

Fig 1 (a)

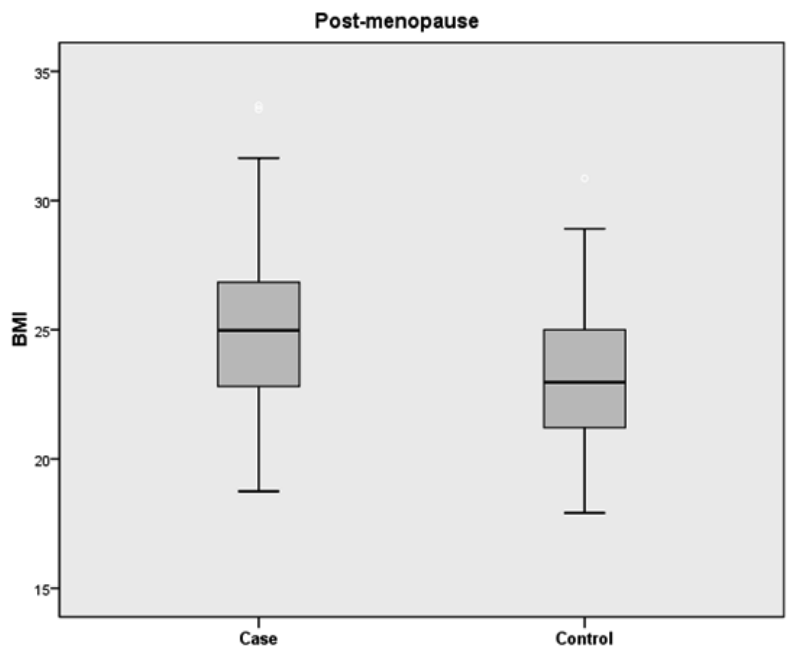

Fig 1 (b)

Figure 1. Comparisons of BMI categories according to menopausal status

\section{Results}

The characteristics and distributions of the subjects are shown in Table 2. The t-test result for the age distribution of the breast cancer and control groups was $\mathrm{p}=0.35$, showing no statistically significant difference. However, the BMI was higher $(\mathrm{p}<0.04)$ and the total energy expenditure was lower $(\mathrm{p}<0.03)$ in the breast cancer group than in the control group. Figure 1 shows the comparison box plots for BMI and menopausal status (Fig. 1(a) - BMI in the pre-menopausal group and Fig. 1(b) - BMI in the post-menopausal group). While pre-menopausal women with breast cancer had a higher BMI than that control individuals $\left(23.7 \pm 14.6\right.$ vs. $\left.21.9 \pm 10.4 \mathrm{~kg} / \mathrm{m}^{2}\right)$, the difference was not statistically significant $(\mathrm{p}<0.07)$. However, post-menopausal women with breast cancer had a significantly higher BMI than that control individuals $(24.9 \pm 13.6$ vs. $23.6 \pm 12.3, \mathrm{p}<0.04)$. Therefore, increased BMI may affect the incidence of breast cancer.

Table 3. General characteristics of breast cancer patients and normal subjects: sums of the daily intake of nutrients

\begin{tabular}{|l|c|c|c|c|}
\hline \multicolumn{1}{|c|}{ Nutrients } & $\begin{array}{c}\text { Breast cancer } \\
(\text { mean } \pm \text { SD) }\end{array}$ & $\begin{array}{c}\text { Controls } \\
(\text { mean } \pm \text { SD) }\end{array}$ & $\wedge p$ & $t p$ \\
\hline Total calories $(\mathrm{kcal})$ & $1711.1 \pm 449.6$ & $1726.4 \pm 595.6$ & 0.82 & \\
\hline Vegetable protein $(\mathrm{g})$ & $34.9 \pm 10.1$ & $37.8 \pm 14.2$ & 0.16 & 0.23 \\
\hline Animal protein $(\mathrm{g})$ & $23.4 \pm 13.7$ & $22.9 \pm 12.5$ & 0.78 & 0.69 \\
\hline Vegetable fat $(\mathrm{g})$ & $17.1 \pm 11.3$ & $16.4 \pm 9.5$ & 0.40 & 0.46 \\
\hline Animal fat $(\mathrm{g})$ & $17.1 \pm 11.3$ & $15.9 \pm 9.5$ & ${ }^{*} 0.04$ & ${ }^{*} 0.02$ \\
\hline Glucose $(\mathrm{g})$ & $294.9 \pm 83.3$ & $302.1 \pm 105.5$ & 0.62 & 0.81 \\
\hline Dietary fiber $(\mathrm{g})$ & $17.7 \pm 6.2$ & $20.1 \pm 8.1$ & ${ }^{* *} 0.009$ & ${ }^{* *} 0.004$ \\
\hline
\end{tabular}

The results were analyzed statistically using t-tests $\left({ }^{\wedge} \mathrm{p}\right.$ : crude $\mathrm{t}$-test; $\uparrow \mathrm{p}$ : adjusted for total calories).

${ }^{*} \mathrm{p}<0.05$ compared to the control.

${ }^{* *} \mathrm{p}<0.005$ compared to the control.
Table 4. Odds ratios and 95\% CIs of breast cancer risk in relation to obesity factor (intakes of animal fat and dietary fiber, BMI, and physical activity) category according to menopausal status in all subjects

\begin{tabular}{|c|c|c|c|c|c|}
\hline \multirow{2}{*}{\multicolumn{2}{|c|}{ Factors }} & $\begin{array}{c}\text { Pre- } \\
\text { menopause }\end{array}$ & \multirow{2}{*}{$p$-value } & $\begin{array}{c}\text { Post- } \\
\text { menopause }\end{array}$ & \multirow{2}{*}{$p$-value } \\
\hline & & $\begin{array}{c}\text { Odds ratio } \\
(95 \% \mathrm{Cl})\end{array}$ & & $\begin{array}{l}\text { Odds ratio } \\
(95 \% \mathrm{Cl})\end{array}$ & \\
\hline \multirow{3}{*}{ Animal fat } & \multicolumn{5}{|l|}{ Reference } \\
\hline & $1^{\text {st }}$ vs. $2^{\text {nd }}$ & $\begin{array}{c}1.14 \\
(0.42-1.82)\end{array}$ & $<0.05$ & $\begin{array}{c}1.08 \\
(0.21-1.92)\end{array}$ & $<0.04$ \\
\hline & $1^{\text {st }}$ vs. $3^{\text {rd }}$ & $\begin{array}{c}1.28 \\
(0.39-1.71)\end{array}$ & $<0.01$ & $\begin{array}{c}1.17 \\
(0.22-1.85)\end{array}$ & $<0.04$ \\
\hline \multirow{3}{*}{$\begin{array}{l}\text { Dietary } \\
\text { fiber }\end{array}$} & \multicolumn{5}{|l|}{ Reference } \\
\hline & $1^{\text {st }}$ vs. $2^{\text {nd }}$ & $\begin{array}{c}0.95 \\
(0.51-1.87)\end{array}$ & $<0.02$ & $\begin{array}{c}0.89 \\
(0.69-2.02)\end{array}$ & $<0.05$ \\
\hline & $1^{\text {st }}$ vs. $3^{\text {rd }}$ & $\begin{array}{c}0.84 \\
(0.48-1.98)\end{array}$ & $<0.01$ & $\begin{array}{c}0.82 \\
(0.71-1.98)\end{array}$ & $<0.03$ \\
\hline \multirow{3}{*}{ BMI } & \multicolumn{5}{|l|}{ Reference } \\
\hline & $1^{\text {st }}$ vs. $2^{\text {nd }}$ & $\begin{array}{c}1.09 \\
(1.01-2.68)\end{array}$ & $<0.34$ & $\begin{array}{c}1.68 \\
(1.15-2.95)\end{array}$ & $<0.001$ \\
\hline & $1^{\text {st }}$ vs. $3^{\text {rd }}$ & $\begin{array}{c}1.24 \\
(1.04-2.59)\end{array}$ & $<0.15$ & $\begin{array}{c}1.95 \\
(1.11-2.78)\end{array}$ & $<0.001$ \\
\hline \multirow{3}{*}{$\begin{array}{l}\text { Physical } \\
\text { activity }\end{array}$} & \multicolumn{5}{|l|}{ Reference } \\
\hline & 1 st $v s .2^{\text {nd }}$ & $\begin{array}{c}0.94 \\
(0.87-1.86)\end{array}$ & $<0.09$ & $\begin{array}{c}1.58 \\
(1.14-2.01)\end{array}$ & $<0.01$ \\
\hline & $1^{\text {st }}$ vs. $3^{\text {rd }}$ & $\begin{array}{c}0.85 \\
(0.65-1.66)\end{array}$ & $<0.02$ & $\begin{array}{c}2.11 \\
(1.08-2.75)\end{array}$ & $<0.001$ \\
\hline
\end{tabular}

Odds ratios and 95\% confidence intervals were estimated using ordinal logistic regression models based on the median of each factor (animal fat, dietary fiber, BMI, and physical activity). The calculated odds ratio was adjusted for age, parity, family history, breastfeeding, and alcohol consumption. 
The results of the nutritional analysis based on the FFQ (Tab. 3) showed that although the total amount of calories consumed by control individuals was slightly higher than that consumed by patients with breast cancer, the breast cancer group had a significantly lower intake of dietary fiber $(\mathrm{p}<0.009)$ and a higher intake of animal fat $(p<0.02)$ than the control group after adjusting for total calories.

In order to investigate obesity factors (nutrient intake, BMI, and physical activity) associated with breast cancer according to menopausal status, we divided these factors into tertiles (Tab. 4). We performed logistic regression to evaluate the association between obesity factors and the risk of breast cancer. For all factors, the multivariable-adjusted (age, parity, family history, breastfeeding, and alcohol consumption) odds ratios of incidences of breast cancer for the highest vs. the lowest tertiles of obesity factors were statistically significant in all of the subjects. However, post-menopausal women had more association between the highest tertiles of obesity factors $(\mathrm{OR}=1.17, \mathrm{p}<$ 0.04 for animal fat; $\mathrm{OR}=0.82, \mathrm{p}<0.03$ for dietary fiber; $\mathrm{OR}=$ $1.95, \mathrm{p}<0.001$ for BMI; OR $=2.11, \mathrm{p}<0.001$ for physical activity) and incidences of breast cancer than pre-menopausal ones, and the association was statistically significant for the BMI factor in the latter group.

\section{Discussion}

The results of the present study support the hypothesis that specific nutrient intakes and physical activity differentially affect the development of breast cancer. We found that breast cancer patients had a lower vegetable and fruit intake and a 30\% lower physical activity level than control individuals and that the breast cancer group also consumed more animal fat. In the case of BMI, the results were different since in the highest tertiles, post-menopausal women had a statistically significantly higher risk for breast cancer $(\mathrm{OR}=1.95, \mathrm{CI}=1.12-2.78)$, but this risk was not statistically significant in pre-menopausal women. Therefore, our findings indicate an association between higher BMI and an increased incidence of breast cancer in post-menopausal women, with an increased incidence of breast cancer among pre-menopausal women with high-fat diets [18, 19, 20, 21]. In an additional analysis of the intake of animal fat and dietary fiber in pre-menopausal and post-menopausal women, a comparison of the intake of animal fat $(\mathrm{p}<0.01)$ and dietary fiber $(\mathrm{p}<0.03)$ between breast cancer patients (animal fat $(\mathrm{g})$ $=18.9 \pm 8.6$ and dietary fat $(\mathrm{g}) 15.6 \pm 6.2)$ and the control group (animal fat $(\mathrm{g})=17.2 \pm 9.0$ and $18.1 \pm 7.8$ ) showed a significant difference in the pre-menopausal group. However, in post-menopausal women, the breast cancer (dietary fat $(\mathrm{g})=18.5 \pm 5.9$ ) and control groups $(21.0 \pm 8.7)$ only showed a significant difference in the intake of dietary fiber $(\mathrm{p}<0.04)$.

As shown in Table 4, our results demonstrate different mechanisms in the associations of obesity with the prevalence of breast cancer in pre- and post-menopausal women. That is, pre-menopausal women had a higher incidence of breast cancer than post-menopausal women due to their higher intake of animal fat.

Our findings were that in the case of post-menopausal women, higher levels of BMI and physical activity were more associated with breast cancer than was food consumption style. High BMI is known to increase the prevalence of breast cancer and its recurrence [20]. Among lifestyle factors related to the development of breast cancer, low-quality, hyper-caloric diets with hyper-caloric and sedentary habits are the greatest risk factors for breast cancer occurrence [18]. In developed coun- tries, the incidence of breast cancer increases with age; thus, the age-specific incidence rates of breast cancer rise steeply from approximately 70 years of age, with the highest rates occurring at approximately 75 to 80 years of age $[19,20,21,22,23,24]$. Breast cancer patients who walked for 30 minutes or more for more than six days per week and those who consumed five or more fruits and vegetables daily had higher survival rates than those who did not [25]. Therefore, it is important to maintain appropriate body weight to increase survival rates after the diagnosis of breast and other cancers. In addition, it is important to promote metabolism through regular exercise and balanced meals. The WHO recommends over $600 \mathrm{MET} /$ week of exercise for health [26] and a systematic review of breast cancer also suggested that exercise reduced the onset of breast cancer as well as other diseases such as heart disease and diabetes. Thus, a minimum of 3,000-4,000 MET/week of exercise is recommended [27]. According to the Korean National Health and Nutrition Survey (KNHANS) conducted between 1975 and 2001, the Korean dietary intake has gradually changed from a traditional diet to a largely Western diet. Although the total caloric intake has declined by $17.3 \%$, there has been a great increase in the intake of animal products, from 14.3 to $91.7 \mathrm{~g}$, during this time [28]. In a similar period (1975 to 2001), obesity began to increase rapidly. The KNHANS survey found that the mean BMI in Korea changed from $22.1 \mathrm{~kg} / \mathrm{m}^{2}$ in 1995 to $23.0 \mathrm{~kg} / \mathrm{m}^{2}$ in 1998 and 23.4 $\mathrm{kg} / \mathrm{m}^{2}$ in 2001 [29]. The increase in obesity in Korea is attributed to lifestyle changes in the form of a shift from the consumption of traditional rice- and vegetable-based meals to the consumption of high-fat, energy-rich foods and reduced physical activity [29]. Adult women have shown increased rates of obesity since the 1990s and the number of breast cancer patients per 100,000 women has also increased sharply $(16.7,20.3,23.0,31.9,40.5$, $46.8,57.5$, and 67.2 people every second year from 1996 to 2010) [1].

A potential limitation in the present study was that participation in recreational activities may not be comparable to participation in occupational activity, where physical activity is not standardized. In addition, the questionnaire study depended on the memory of the subjects. Thus, the exact age of menarche may be unclear. Despite these limitations, the results of the study can be useful in understanding the epidemiology of breast cancer in Korea.

Although women with genetic factors have an unavoidably increased incidence of breast cancer compared to that in women without these genetic factors, exercise and dietary habits may help to decrease the incidence of breast cancer in this population due to modifiable factors, such as obesity, that are also associated with breast cancer.

\section{Conclusion}

In conclusion, diet and exercise, which are the main determinants of obesity, have different effects on the incidence of breast cancer. Thus, performing regular exercise, eating lowenergy foods, and maintaining a healthy weight are required to lower the incidence of breast cancer.

\section{Acknowledgements}

Funding for this paper was provided by Namseoul University. 


\section{Literature}

1. National Cancer Center. Cancer incidence in Korea Annual report of cancer statistics in Korea in 2015. Retrieved Oct 15, 2018, from http://ncc.re.kr/main.ncc?uri=english/sub04_ statistics.

2. Carioli G., Bertuccio P., La Vecchia C., Malvezzi M., Negri E., Rodriguez T. (2017). Trends and predictions to 2020 in breast cancer mortality in Europe. Breast 36, 89-95.

3. Jung E.J., Kang D., Kim Y., Park S.K., Yoo K.Y. (2011). Risk factors and control strategies for the rapidly rising rate of breast cancer in Korea. Journal of Breast Cancer 14, 79-87.

4. Baade P.D., Cramb S.M., Yip C.H., Youlden D. (2014). Incidence and mortality of female breast cancer in the Asia-Pacific region. Cancer Biology and Medicine 11(2), 101-115.

5. Kang H.T., Shin H.Y. (2017). Recent trends in the prevalence of underweight, overweight, and obesity in Korean adults: The Korean national health and nutrition examination survey from 1998 to 2014. Journal of Epidemiology 27(9), 413419.

6. Iyengar N.M., Hudis C.A., Dannenberg A.J. (2013). Obesity and inflammation: New insights into breast cancer development and progression. In: D.S. Dizon (ed.), American Society of Clinical Oncology Educational Book (pp. 46-51), Alexandria, VA: American Society of Clinical Oncology. DOI: 10.1200/EdBook_AM.2013.33.46.

7. DeSanitis C., Ma. J., Bryan L., Jemal A. (2014). Breast cancer statistics 2013. Cancer Journal for Clinicians 64(1), 52-62. DOI: 10.3322/caac.21203.

8. Torre L.A., Bray F., Siegel R.L., Ferlay J., Lortet-Tieulent J., Jemal A. (2015). Global cancer statistics, 2012. Cancer Journal for Clinicians 65(2), 87-108. DOI: 10.3322/caac.21262.

9. Wu Y., Kang S., Zhang D. (2013). Physical activity and risk of breast cancer: A meta-analysis of prospective studies. Breast Cancer Research and Treatment 137(3), 869-882. DOI: 10.1007/s10549-012-2396-7.

10. Aune D., Norat T., Leitzmann M., Tonstad S., Vatten L.J. (2015). Physical activity and the risk of type 2 diabetes: A systematic review and dose-response meta-analysis. European Journal of Epidemiology 30(7), 529-542. DOI: 10.1007/ s10654-015-0056-z.

11. Sattelmair J., Pertman J., Ding E.L., Kohl H.W. 3rd, Haskell W., Lee I.M., (2011). Dose response between physical activity and risk of coronary heart disease: A meta-analysis. Circulation 124(7), 789-795. DOI: 10.1161/CIRCULATIONAHA.110.010710.

12. Liu L., Shi Y., Li T., Qin Q., Yin J., Pang S., Nie S., Wei S. (2015). Leisure time physical activity and cancer risk: Evaluation of the WHO's recommendation based on 126 highquality epidemiological studies. British Journal of Sports Medicine 50(6), 372-378. DOI: 10.1136/bjsports-2015-094728.

13. World Health Organization. Recommendations on physical activity for health. Retrieved Jul 14, 2018. from: http://www. who.int/dietphysicalactivity/factsheet_recommendations/ en/. 14. Lahart I.M., Metsios G.S., Nevil A.M., Carmichael A.R. (2015). Physical activity, risk of death and recurrence in breast cancer survivors: A systematic review and meta-analysis of epidemiological studies. Acta Oncologica 54(5), 635-654. DOI: 10.3109/0284186X.2014.998275.

15. Wiklund P. (2016). The role of physical activity and exercise in obesity and weight management: Time for critical appraisal. Journal of Sport and Health Science 5(2), 151-154. DOI: 10.1016/j.jshs.2016.04.001.
16. Diuric Z., Ellsworth J.S., Weldon A.L., Ren J., Richardson C.R., Resnicow K., Newman L.A., Hayes D.F., Sen A. (2011). A diet and exercise intervention during chemotherapy for breast cancer. The Open Obesity Journal 3, 87-97. DOI: 10.2174/1876823701103010087.

17. International Physical Activity Questionnaire Research Committee. Guidelines for data processing and analysis of the International Physical Activity Questionnaire (IPAQ) Short and long forms. Retrieved Jul 19, 2018. from: http:// www.ipaq.ki.se/scoring.pdf.

18. Garofalo C., Koda M., Cascio S., Sulkowska M., KanczuqaKoda L., Golaszewska J. et al. (2016). Increased expression of leptin and the leptin receptor as a marker of breast cancer progression: Possible role of obesity-related stimuli. Clinical Cancer Research 12(5), 1447-1453. DOI: 10.1158/10780432.CCR-05-1913.

19. Sparano J.A., Wang M., Zhao F., Stearns V., Martino S., Ligibel J., Perez E.A. et al. (2012). Obesity at diagnosis is associated with inferior outcomes in hormone receptor-positive operable breast cancer. Cancer 118(23), 5937-5946. DOI: $10.1002 /$ cncr.27527.

20. Rose D.P., Vona-Davis L. (2010). Interaction between menopausal status and obesity in affecting breast cancer risk. Maturitas 66(1), 33-38. DOI: 10.1016/j.maturitas.2010.01.019.

21. De Pergola G, Silvestris F. (2013). Obesity as a major risk factor for cancer. Journal of Obesity 2013, ID 291546. DOI: $10.1155 / 2013 / 291546$.

22. Bishop K., Howlader N., Miller D., Noone A.M., Kosary C.L., Krapcho M.. National Cancer Institute. SEER Cancer Statistics Review, 1975-2014,. from: https://seer.cancer.gov/ csr/1975_2014/.

23. Howlader N., Noone A.M., Krapcho M., Miller D., Bishop K., Kosary C.L., Yu M. et al. (eds) SEER Cancer Statistics Review, 1975-2014. Bethesda, MD: National Cancer Institute, Retrieved Jun 3, 2018 from https://seer.cancer.gov/ csr/1975_2014/.

24. Office for National Statistics. Cancer registration statistics, England: 2016. Retrieved Jun 14, 2018. from: https://www. ons.gov.uk/peoplepopulationandcommunity/healthandsocialcare/conditionsanddiseases/bulletins/cancerregistrationstatisticsengland/2016.

25. Jung K.W., Won Y.J., Kong H.J., Oh C.M., Seo H.G., Lee J.S., (2013). Cancer statistics in Korea: Incidence, mortality, survival and prevalence in 2010. Cancer Research and Treatment 45(1), 1-14. DOI: 10.4143/crt.2013.45.1.1

26. Pierce J.P., Marcia L., Stefanick M.L., Shirley W., Flatt S.W., Natarajan L., Sternfeld B. et al. (2007). Greater survival after breast cancer in physically active women with high vegetable-fruit intake regardless of obesity. Journal of Clinical Oncology 25(17), 2345-251. DOI: 10.1200/JCO.2006.08.6819.

27. World Health Organization, Surveillance and PopulationBased Prevention Diseases Department. Global Physical Activity Questionnaire (GPAQ). Analysis Guide. Retrieved Jul 9, 2018. from: http://www.who.int/chp/steps/resources/ GPAQ_Analysis_Guide.pdf.

28. Kyu H.H., Bachman V.F., Alexander L.T., Mumford J.E., Afshin A., Estep K., Vermann J.L. et al. (2016). Physical activity and risk of breast cancer, colon cancer, diabetes, ischemic heart disease, and ischemic stroke events: Systematic review and dose-response meta-analysis for the Global Burden of Disease Study 2013. BMJ 354, i3857. DOI: 10.1136/ bmj.i3857.

29. National Health and Nutrition Examination Survey. Korean Center for Disease Control and Prevention, National He- 
alth and Nutrition Survey, 1975 and 2001. Retrieved Jan 4, 2018. from: https://www.cdc.gov/nchs/ppt/nchs2015/Porter_Monday_SalonE_A6.pdf.

30. Kim D.M., Ahn C.W., Nam S.Y. (2005). Prevalence of obesity in Korea. Obesity Reviews 6(2), 117-121. DOI 10.1111/j.1467789X.2005.00173.x.

31. Garofalo C., Koda M, Cascio S., Sulkowska M, KanczuqaKoda L., Golaszewska J. et al. (2016). Increased expression of leptin and the leptin receptor as a marker of breast cancer progression: Possible role of obesity-related stimuli. Clinical Cancer Research 12(5), 1447-1453. DOI: 10.1158/10780432.CCR-05-1913.

Submitted: October 3, 2019.

Accepted: November 21, 2019. 